\title{
Yabancı Dil Olarak Türkçenin Öğretiminde Kullanılan Temel Seviye Fiillerin İstem(Valenz) Görünümleri
}

\author{
Cihat Burak Korkmaz*
}

Makale Geliş Tarihi: 26/12/2020

Makale Kabul Tarihi: 17/01/2021

DOI: $10.35675 /$ befdergi. 847267

$\ddot{O} z$

Türkçenin sondan eklemeli bir dil olmast, cümle içerisinde yer alan filin sahip olduğu anlam özelliğine dayalı olarak fiilden etkilenen unsurlara getirilen eklerin değişiklik göstermesi önemli bir dil bilgisi özelliği olarak öne çıkmaktadır. Bu bağlamda gerek kelime öğretimi gerekse dil bilgisi ögretimi süreçlerinde fiillerin kullanım özelliklerine ve anlam karşılıklarına bağlı olarak yüklendikleri durumlarıyla birlikte öğretimi hem öğrenmeyi kalıcl hâle getirecek hem de biçimbilgisel istemlere (durum ekleri) bağlı olarak yapılan üretici dil becerileri yanlışlarını en az seviyeye indirecektir. Bu çalışmanın amacı, yabancı dil olarak Türkçenin ögretiminde kullanılan temel seviye fillerin istem(valenz) görünümlerini incelemektir. Çalışmada durum tespiti yöntemi kullanılmış olup, beş öğreticiden A1 seviyesinde kullanılan toplam 161 fiilin biçimbilgisel istemleri ile ilgili kodlamaya dayalı bilgi alınmıştır. Güvenirlik oranı Miles ve Huberman'ın formülü [(Güvenirlik = görüş birliği / görüş birliği + görüş ayrllı̆̆l)x100] kullanılarak \%91 olarak hesaplanmıştır.

Anahtar Kelimeler: Fiiller, istem(valenz), yabancı dil olarak Türkçenin öğretimi

\section{The Valency Profiles of Basic Level Verbs Used in The Teaching Turkish as a Foreign Language}

\begin{abstract}
The fact that Turkish is a agglutinative language, the variation of the suffixes brought to the elements affected by the verb based on the meaning feature of the verb in the sentence as an important grammatical feature. The situations in which verbs are loaded depending on their usage characteristics and meaning equivalents, the teaching will make the learning permanent and the productive language skills based on morphological valencies (case suffixes) will minimize the mistakes. The aim of this study is to examine the valencies of the basic level verbs used in teaching Turkish as a foreign language The situation determination method was used in the study, and coding-based information about the morphological valencies of a total of 161 verbs used at Al level was obtained from five instructors. The reliability rate was calculated as $91 \%$ using Miles and Huberman's formula (Reliability Percentage $=$ Agreement/(Total Agreement + Disagreement $) x 100)$.
\end{abstract}

Keywords: Valency, verbs, teaching Turkish as a foreign language

\section{Giriş}

Sözcük türü olarak Banguoğlu (1990), "Bir k1lış, bir oluş veya durumu, toplu bir deyimle olup biteni anlatan kelimeye fiil denir." demektedir (s. 408). Ergin fiilleri,

\footnotetext{
* Ankara Yıldırım Beyazıt Üniversitesi, Ankara, Türkiye, cbkkrkmz@gmail.com ORCID: 0000-00034383-3443
}

Kaynak Gösterme: Korkmaz, C. B. (2021). Yabancı dil olarak Türkçenin öğretiminde kullanılan temel seviye fiillerin istem(valenz) görünümleri. Bayburt Eğitim Fakültesi Dergisi, 16(Özel Sayı), 91-107. https://doi.org/10.35675/befdergi.847267 
hareketleri karşılayan kelimeler, hareketleri ise nesnelerin zaman ve mekân içindeki her türlü etkinlikleri olarak değerlendirmektedir (1992). Dizdaroğlu ise fiilin eylem bildiren sözcük olduğunu ve her fiilde eylem, zaman ve şahıs bildiren üç kavramın var olduğunu belirtir (1963). Korkmaz da fiillerin iş ve hareket bildiren sözcükler olduğunu, karşıladıkları hareketler ile zaman ve mekân kapsamı içinde nesne ve kavramlarla ilgili her türlü oluş, kılış, kılınış ve durumları bildirdiğini belirtir (2003).

Fiiller, bir cümlenin temel unsurudur. Çeşitli eklerle çekimlenen fiiller cümlede yüklem göreviyle kullanılmaktadır. Yüklemler cümlenin özne, nesne ve tümleçlerini aldığ1 eklerle kendi bünyesinde bulundurur. "Fiiller çekimlendikleri zaman cümle değeri taşırlar. Çekim eklerinden şahıs ekleri cümlenin öznesini ifade eder. Cümlenin ana unsuru olan özne ve yüklem de fiil üzerinde toplanmış olur" (Akıncı, 2007, s. 2).

"Murat eve gidiyor." cümlesinde git- fiili şimdiki zamanın üçüncü tekil şahsı ile çekimlenmiştir. Gitmek eylemini Murat şahsı gerçekleştirirken gitmek eyleminin etkilendiği nesne $e v$, eylemin yönü de yönelme durumunda [-(y)A] yapılmaktadır. Örnekten de anlaşılacağı üzere çekimli fiil özneyi, nesneyi ve nesnenin durumunu da etkilemektedir.

Çağdaş dil bilimde istem (valenz) teorisi Lucien Tesnière tarafindan üretilmiş olup cümlede fiilden yola çıkan Tesnière cümlenin diğer ögelerini eyleyen (actants) ve tümleyen (circontants) olmak üzere ikiye ayırmıştır. Fiillerin belirli bir sayıda eyleyen alma kabiliyetlerini atomun birleşim değerleriyle karşılaştıran Tesnière; eyleyenlerin (isim ve isimle eş-değerde olan ögeler) zorunlu, tümleyenlerin ise (zaman, yer, niteleme zarfları) seçimli olduğunu kabul etmiştir (Barlas, 2015).

"Tesnière'in dilbilim alanına aktardığı istem aslında bir kimya terimidir. Doğada atomlar bir arada bulunabilmek için birbiriyle bir tür iletişime girerler. Bu iletişim bir tür kimyasal bağ kurma ilişkisidir. Belli atomlar arasında bir birleşim kapasitesi vardır ve bu kapasite yeni bir kimyasal bağ oluşturur. Sözgelimi bir su molekülünün oluşması için iki hidrojen ve bir oksijen atomu gerekmektedir. Su molekülünün bu atom gereksinimi kimyada onun değerlik yapısı; yani istemi olarak adlandırılır. Tesnière de tümcede eylemden yola çıkarak eylemlerin belli sayıda katılanı yönetme özelliğini atomun değerlik yapısıyla karşılaştırmış ve bu süreci ifade etmek için bu terimi kullanmıştır" (Tesnière, 2015, s. 239'dan akt. Aydın Özkan, 2017, s. 71).

Cümlenin yüklem görevli kelimesini veya kelime grubunu meydana getiren yüklem bileşenleri gerektirdikleri üyelerin sayısına göre bir, iki, üç yapısal boşluklu olarak sınıflandırılabilirler (Bussmann, 2006, s. 213'den akt. Aydın Özkan, 2017). Aşağıda bu duruma ait somut örnekler verilirken yüklemi oluşturan unsurun $X$, diğer unsurlarında hiyerarşik olarak $V, Y, Z$ sembolleri ile aktarıldığı görülmektedir:

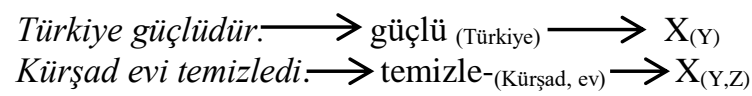




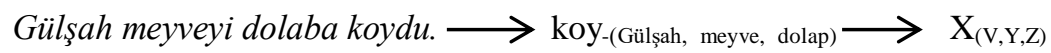

Yukarıda yer alan üç örnekte de cümlelerin belirleyici unsurları yüklem görevli kelimelerdir. Bu kelimeler karşıladıkları eylem veya belirttikleri durum itibarıyla en az bir veya birkaç tamamlayıcı üyeye ihtiyaç duymaktadırlar. Bu üyeler de doğru anlamı tamamlayabilmek için yüklemlerin ihtiyaç duyduğu durumlarla birlikte kullanılmaktadırlar.

İstem kavramı ile ilgili yapılan çalışmalar kısıtlı olmakla beraber Türkiyat ve dilbilim çalışmalarında son yıllarda ilgi duyulan bir terim olarak değerlendirilmektedir. Bu terim Türkçede; fiil rejimi (Korkmaz, 1995), istem (Banguoğlu 1990), durum ekli tamlayıcı (Kahraman, 1996), durum belirleyici (Uzun, 2004), değerlik (Ozil, 1990), valenz (Uğurlu, 2001; Gümüşatam, 2014), birleşim değeri (Vardar, 2002), hâl eki nöbetleşmesi (Demirci, 2007), fiil-tamlayıcı ilişkisi (Özkan, 1991; Karahan, 1997; Ersoy, 2006; Yalkın, 2016) terimleri ile karşılanmaktadır (Dolunay, İpek \& Karabuğa, 2018). Bu çalışmalarla beraber istem terimi üzerine Türk lehçelerinin hemen hepsi ile ilgili yapılan çeşitli lisansüstü çalışmalar (Güller, 2019; Aydın Özkan, 2017; Yılmaz, 2016; Baytürk, 2015; Barlas, 2015; Çiçekli, 2013; Çetinkaya, 2012, Doğan, 2011; Çimen 2009; Uzunboy, 2008; Atacık, 2008) ise ilgili kavramın Türk dili açısından önemli bir konu olduğunu göstermektedir.

\section{Biçimbilgisel (Morfolojik) İstem Görünümünde Durum Ekleri}

"Fiiller söz dizimsel istem düzeyinde açılan boşlukları ilgili anlam değişkesine göre belirli durum ekli biçim birimlerle doldurur. Her fiil, her durum ekli tamlayıcıyı alamaz ve yönetemez. Fiil, söz dizimsel düzeyde belli sayıda tamlayıcıyı belli durum biçim birimlerle yönetebilir. Türkçedeki bu durum morfolojik istem terimiyle karşılanabilir" (Doğan, 2011, s. 59). Biçimbilgisel istem düzeyi, istemin sözdizimsel görünümünün biçimbilimsel açıklaması olmakla birlikte eylemin mantıksal yapıda yarattığı boşlukların ve bu boşlukları dolduran anlamsal katılanların yüzey yapıda çeşitli yapılarla biçimbilgisel olarak işaretlenmesidir (Aydın Özkan, 2017). "Biçimbilgisel istem, fiillerin kendi anlam özelliklerine göre açtıkları istem boşluklarını tamlayıcılara ulanan belirli durum ekli biçimbirimlerle işaretleme gücüdür" (Dolunay vd., 2018, s. 401). Bu tanımlardan hareketle, fiillerin sahip oldukları veya bağlamdan hareketle üstlendikleri anlamalara uygun olarak kendisini tamamlayan kelime veya kelime gruplarına ekledikleri durum ekleri biçimbilgisel istemleri ortaya çıkarmaktadır sonucuna ulaşılmaktadır. Çünkü fiillerin aldıkları tamlayıcılar fiillerin anlamlarıyla bağlantılıdır. Yani fiilin anlamı ile tamlayıcı arasında bir ilişki vardır (Özkan, 1991). Bu sebeple cümlenin yöneticisi olan fiil, yüzey yapıda açmış olduğu istem boşluklarının hangi tamlayıcılarla doldurulacağını da belirlemektedir (Uzunkaya, 2018).

Türkiyat çalışmalarında biçimbilgisel istemlerde birinci başlıkta bahsedildiği üzere durum ekli tamlayıcı, durum belirleyici, hâl eki nöbetleşmesi, fiil-tamlayıc ilişkisi gibi durum eklerinin merkez yörüngesinde ilerlemektedir. Türkçede dil bilgisel ilişkiler isimlerin durum ekli tamlayıcıları ile gerçekleşmektedir ve durum ekleri istem teorisi bakımından en tipik tamlayıcı sınıfını oluşturmaktadır 
(Uzunkaya, 2018). "İstem terimi Türkoloji alanında daha çok 'fill-tamlayıcı ilişkisi' terimi ile karşılanmaktadır. Ancak bu terim, aslında modern istem çalışmalarında 'biçimbilgisel istem (morphological valency)' terimiyle ifade edilmektedir" (Dolunay vd., 2020, s. 510).

Buna rağmen biçimbilgisel istem düzeyi, dillerin kendi tipolojik özellikleri ile yakından ilgilidir. Her dilde biçimbilgisel istem farklılıklar gösterir ve eylemin biçimbilgisel istemi farklı unsurlar aracılığıyla ortaya çıkar (Aydın Özkan, 2017; Uzunkaya, 2018). "Kimi dillerde sözcükler yalın durumda bulunur; sözcüklerin teklik, çokluk ekleri, dişilik, erkeklik veya cinssizlik tanımlıkları vardır. Kimi dillerde ad çekimi yoktur; fiillere eşlik eden edatlarla/takılarla istenilen anlatım gerçekleştirilir. Kimi dillerde ise hem takılar kullanılır hem de adların çekimi yapılır" (Nurlu, Özkan, Kutlu, Korkmaz \& İlgün, 2017, s. 6). Somut bir örnek verilecek olursa: "Türkçe dinle- eylemi belirtme durumuyla işaretlenirken, eylemin Almanca karşılığı zuhören yönelme durumuyla işaretlenir” (Aydın Özkan, 2017, s. 85).

Yabancı dil olarak Türkçenin öğretiminde dil bilgisi öğretimi özellikle temel seviyenin A1 kurunda dilin kuralları dünyasına girişin ilk basamağı olması sebebiyle önem taşımaktadır. Çünkü bu seviye; öğrenici için dilin ses, şekil, kelime ve cümle dünyasına girişin en önemli basamağıdır. Özelikle bu seviyede yoğun bir dil bilgisi öğretimi yapılırken Türkçenin biçimbilgisel özelliklerinin temel kuralları A1 kurunda ele alınmaktadır. "Yabancı dil öğretiminde dört temel becerinin gelişimiyle birlikte dil bilgisi öğretimine odaklanıldığı görülmektedir. Dilin bir kurallar bütünü olduğu düşünüldüğünde dil bilgisinin önemi yadsınamaz" (Kara Özkan, 2020, s. 129). Yapılan birçok çalışmada (Mert, 2003; Açık 2008; Kara, 2010; Karababa, 2009; Şahin 2013; Atagül \& Cevher, 2015; Boylu; 2014; Melanlığlu, 2012; Çangal \& Başar, 2018) Türkçeyi yabancı dil olarak öğrenen hedef kitlenin her seviyede ve her beceride biçimbilgisel istem (durum ekleri) ile ilgili yanlışlar yaptığ görülmektedir. $\mathrm{Bu}$ anlamda modern dil öğretim yaklaşımlarında dil bilgisi öğretimi başlı başına bir beceri olarak ele alınmazken Türkçe gibi biçimbilgisel birçok kurala ve istisnaya sahip olan eklemeli bir dilin yabancı dil olarak öğretiminde dil bilgisi kuralları öğretimin merkezinde yer almaktadır. Ayrıca yabancılara Türkçe öğretiminde ders kitaplarında dil bilgisi yapılarına ilişkin açıklamalara ya da dil bilgisi öğretimi için ayrı olarak hazırlanmış materyallere ihtiyaç duyulmaktadır (İltar \& Dündar, 2018). Yabancı dil olarak Türkçenin öğretiminde durum eklerinin öğretiminde belirli bir sıra izlendiği bilinmektedir. Aşağıda yer alan tabloda ilgili yapıların hangi sırayla ve hangi adlarla öğretildiği ise şöyle gösterilmelidir:

Tablo 1.

Durumlar ve Ekleri

\begin{tabular}{ll}
\hline Durumun Adı & Durum Eki \\
\hline Yalın durum & $\varnothing$ (Ek yok) \\
Belirtme durumu & $-($ y)I veya - i durumu \\
Yönelme durumu & $-(\mathrm{y})$ A veya - e durumu \\
Bulunma durumu & -DA veya - de durumu \\
Ayrılma durumu & -Dan veya - den durumu \\
Araç (Vasıta) durumu & -(y)IlA veya ile durumu \\
\hline
\end{tabular}


Bu noktada öğretici ve alan uzmanlarından beklenen yeterlik, hataların en aza indirilmesi ve doğru öğretimin yapılabilmesi açısından fiillerin biçimbilgisel istem tamlayıcıları ile ilgili yeterli bilgiye sahip olmalarıdır. Çünkü "Türkçenin yabancılara öğretiminde bazı eski alışkanlıkların ve tekniklerin gözden geçirilmesi ve yenilenmesi gerekmektedir. Ad durum eklerinin öğretimi bu konulardan biridir. Ad durum ekleri öğretilirken yeni bazı anlayışların benimsenmesi gereklidir" (Sakallı, 2016, s. 102). Bunula beraber öğretici öğretim yöntem ve tekniklerinde de haberdar olmalıdır (Ustabulut, 2020).

Fiillerin öğretimi yapılırken aynı zamanda farkında olunmadan biçimbilgisel istemlerin (durum ekleri) öğretimi de yapılmaktadır. Böylece bir fiille kullanılan bir veya birden fazla ek ortaya çıkmaktadır. Fiillerin aldığı ekler ile ilgili mevcut görünüm ile bu eklerin öğreticiler tarafından mevcut görünüme göre öğretilmesi öğrenci için daha işlevsel bir öğretim süreci oluşması açısından büyük bir öneme sahiptir. $\mathrm{Bu}$ noktada çalışma konusunun önemine dikkat çekecek ve fiillerin kullanıldıkları anlama veya bağlama göre alabilecekleri bazı eklere ve bu eklerin değişmesine örnekler şöyledir:

Tablo 2.

Örnek Cümleler

\begin{tabular}{ll}
\hline Biçimbilgisel İstem & Örnek Cümle \\
\hline$\varnothing$ & Murat müzik dinliyor. \\
$-(y)$ I veya-i durumu & Murat müziği dinliyor. \\
$-D A$ veya - de duruти & Murat sinıfta müzik dinliyor. \\
- Dan veya - den durumu & Murat radyodan müzik dinliyor. \\
\hline
\end{tabular}

\section{Çalışmanın Amacı ve Önemi}

$\mathrm{Bu}$ çalışmada, A1 seviyesinde Türkçe ögretenlerin sahip olduklart biçimbilgisel istem bilgisinin güvenirliği nedir? sorusuna cevap bulabilmek amaçlanmıştır. $\mathrm{Bu}$ bağlamda öğretici görüşlerinin öğrenci bilgisini doğrudan etkileyeceği düşünüldüğünden ortaya çıkacak sonuçlar çalışmanın önemini belirlemiştir.

\section{Yöntem}

$\mathrm{Bu}$ çalışma nitel araştırma yöntemlerinden biri olan durum çalışması ile desenlenmiştir. Durum çalışması, güncel olan ve araştırmacı kontrolünün değişkenler üzerinde olmadığı durumlarda bu durumun sebeplerini, nedenleri ve sonuçlarını anlamak, tanımlamak ve betimlemek için kullanılan bir araştırma yöntemidir. Durum çalışmasında, sınırları belirlenmiş bir araştırma konusunun gerçek ortamında ayrıntılı olarak betimlenmesi ve incelenmesi söz konusudur. Durum çalışması göre çok boyutlu veri toplamayı gerektiren bir çalışma olup bir veya birkaç durumu kendi sınırları içerisinde bütüncül olarak analiz etmedir (Yıldırım \& Şimşek, 2012). 


\section{Çalışma Materyali ve Katılımcılar}

Yabancı dil olarak Türkçenin öğretiminde kullanılan ve araştırmacı tarafından tespit edilen A1 seviyesindeki fiillere yönelik öğreticiler arasında bir tutarlılık olup olmadığını belirlemek için ise beş öğretici üzerinden kodlayıcı güvenirliği yapılmıştır.

\section{Verilerin Toplanması ve Analizi}

Araştırmada kodlayıcı güvenirliği kapsamında kendileri ile çalışılacak öğreticilere verilmek üzere ders kitabındaki 161 tane fiil araştırmacı tarafından liste haline getirilmiştir. Katılımcılar sunulandan kendilerine sunulan listelerde yer alan fiillerin üzerinde yer alan biçimbilgisel istem tamlayıcılarının kutucuklarına işaret konulması istenmiştir. Her bir öğretici için ayrı ayrı oluşturulan listelere verilen cevap kâğıtlarına demografik bilgilerine bakılmaksızın birden beşe kadar numara verilmiştir.

Katılımcıların yaptıkları işaretlemelerden sonra fiillerin bulunduğu listeler kodlayıcı güvenirliklerini hesaplamak amacıyla çözümlenmiştir. Bu kapsamda araştırmaya katılan 5 öğretmen arasındaki kodlayıcı güvenirliği Miles ve Huberman'ın (1994) formülü [(Güvenirlik = görüş birliği / görüş birliği + görüş ayrılı̆̆l) $x$ 100] kullanılarak hesaplanmıştır. Bu bağlamda çalışmada 5 öğretici tarafindan 14 fiil üzerinde görüş ayrılığ 1 yaşandığı tespit edilmiştir. Bu durumda güvenirlik $=147 / 147+14$ x $100=\% 91$ olarak hesaplanmıştır.

Elde edilen nitel veriler nicelikleri bakımından çözümlenerek frekans değerleri ve fiillerin kaç veya kaçar tane biçimbilgisel istem ile kullanıldığı da sayısal ve oransal değerleri ile hesaplanmıştır.

\section{Bulgular}

Çalışmanın bu bölümünde öğreticilere dağıtılan listelerde yer alan fiillerin hangi biçimbilgisel istemlerle birlikte kullanıldığını işaretlemeleri istenmiştir. Her fiil için istenildiği kadar işaretleme yapılabileceği veya boş bırakma seçeneği de olduğu belirtilmiştir.

\section{Biçimbilgisel İstem Görünümüne İlişkin Öğretici Kodlamaları ile İlgili Bulgular}

Çalışma materyalinden derlenen fiillerin aşağıdaki alfabetik sıralamaya benzer şekilde listelenerek durum eklerini Tablo 1'deki kısa adlandırmaları ile işaretlenmesi sonucunda öğreticilerin ortak cevapları frekans aralığı şeklinde gösterilmiştir. Çalışma grubunun cevaplarının deşifre edilmiş şekli aşağıdaki tabloda yer almaktadır: 
Tablo 3.

Öğretici Görüşleri Bağlamında Biçimbilgisel İstemler

\begin{tabular}{|c|c|c|c|c|c|c|}
\hline Fiiller & Ö1 & Ö2 & Ö3 & Ö4 & Ö5 & $f$ \\
\hline Aç-mak & $-\mathrm{i}$ & $-\mathrm{i}$ & $-\mathrm{i}$ & $\varnothing$ & $-\mathrm{i}$ & 4 \\
\hline A ğr1-mak & $-\mathrm{i}$ & $-\mathrm{i}$ & $-\mathrm{i}$ & $-\mathrm{i}$ & $-\mathrm{i}$ & 5 \\
\hline Al-mak & $\varnothing$,-den & $\varnothing$,-den & $\varnothing$,-den & $\varnothing$,-den & $\varnothing$ & 4 \\
\hline Anla-mak & $-\mathrm{i}$ & $-\mathrm{i}$ & $-\mathrm{i}$ & $-\mathrm{i}$ & $-\mathrm{i}$ & 5 \\
\hline Anlaş-mak & ile & ile & ile & ile & ile & 5 \\
\hline Anlat-mak & $-i,-e$ & $-\mathrm{i},-\mathrm{e}$ & $-\mathrm{i},-\mathrm{e}$ & $-\mathrm{i},-\mathrm{e}$ & $-\mathrm{i},-\mathrm{e}$ & 5 \\
\hline Ara-mak & $-\mathrm{i}$ & $-\mathrm{i}$ & $-\mathrm{i}$ & $-\mathrm{i}$ & $-\mathrm{i}$ & 5 \\
\hline As-mak & $\varnothing,-\mathrm{i}$ & $\varnothing,-\mathrm{i}$ & $\varnothing,-\mathrm{i}$ & $\varnothing,-\mathrm{i}$ & $\varnothing,-\mathrm{i}$ & 5 \\
\hline Atla-mak & $\varnothing,-\mathrm{i}$, -den & $\begin{array}{c}\varnothing,-\mathrm{i},- \\
\text { den }\end{array}$ & $\begin{array}{c}\varnothing,-i,- \\
\text { den }\end{array}$ & $\begin{array}{c}\varnothing,-\mathrm{i},- \\
\text { den }\end{array}$ & $\begin{array}{c}\varnothing,-i,- \\
\text { den }\end{array}$ & 5 \\
\hline At-mak & $\varnothing,-\mathrm{i}$ & $\varnothing,-\mathrm{i}$ & $\varnothing,-\mathrm{i}$ & $\varnothing,-\mathrm{i}$ & $\varnothing,-\mathrm{i}$ & 5 \\
\hline Bak-mak & $-e$ & $-e$ & $-e$ & $-e$ & $-e$ & 5 \\
\hline Banyo yap-mak & $\varnothing$, ile & - de & $\varnothing$, -de & - de & ile & 2 \\
\hline Başla-mak & $-e$ & $-\mathrm{e}$ & $-\mathrm{e}$ & $-\mathrm{e}$ & $-e$ & 5 \\
\hline Bayıl-mak & $\varnothing$ & $\varnothing$ & $\varnothing$ & $\varnothing$ & $\varnothing$ & 5 \\
\hline Beğen-mek & $-\mathrm{i}$ & $-\mathrm{i}$ & $-\mathrm{i}$ & $-\mathrm{i}$ & $-\mathrm{i}$ & 5 \\
\hline Bekle-mek & $\varnothing,-\mathrm{i}$ & $\varnothing,-\mathrm{i}$ & $\varnothing,-\mathrm{i}$ & $\varnothing,-\mathrm{i}$ & $\varnothing,-\mathrm{i}$ & 5 \\
\hline Benze-mek & $-\mathrm{e}$ & $-e$ & $-e$ & $-e$ & $-e$ & 5 \\
\hline Beslen-mek & ile & ile & ile & ile & ile & 5 \\
\hline Bil-mek & $-\mathrm{i}$ & $-\mathrm{i}$ & $-\mathrm{i}$ & $-\mathrm{i}$ & $-\mathrm{i}$ & 5 \\
\hline Bin-mek & $-e$ & $-\mathrm{e}$ & $-e$ & $-e$ & $-e$ & 5 \\
\hline Biriktir-mek & $\varnothing,-\mathrm{i}$ & $\varnothing$ & $\varnothing,-\mathrm{i}$ & $\varnothing,-\mathrm{i}$ & $\varnothing,-\mathrm{i}$ & 4 \\
\hline Bozul-mak & $\varnothing$ & $\varnothing$ & $\varnothing$ & $\varnothing$ & $\varnothing$ & 5 \\
\hline Buluş-mak & ile, -de & ile, -de & ile, - de & ile, -de & ile, -de & 5 \\
\hline Cevap ver-mek & $\varnothing,-\mathrm{e}$ & $\varnothing,-\mathrm{e}$ & $\varnothing,-\mathrm{e}$ & $\varnothing,-\mathrm{e}$ & $\varnothing,-\mathrm{e}$ & 5 \\
\hline Çalış-mak & $\varnothing,-\mathrm{e},-\mathrm{de}$ & $-\mathrm{i}$ & $\begin{array}{c}\varnothing,-\mathrm{e},- \\
\mathrm{de}\end{array}$ & $\begin{array}{c}\varnothing,-\mathrm{e},- \\
\mathrm{de}\end{array}$ & $\begin{array}{c}\varnothing,-\mathrm{e},- \\
\mathrm{de}\end{array}$ & 5 \\
\hline Çal-mak & $\varnothing,-\mathrm{i}$ & $\varnothing,-\mathrm{i}$ & $\varnothing,-\mathrm{i}$ & $\varnothing,-\mathrm{i}$ & $\varnothing,-\mathrm{i}$ & 5 \\
\hline Çık-mak & -den, ile & -den, ile & -den, ile & -den, ile & -den & 4 \\
\hline Danış-mak & $-e$ & $-e$ & $-e$ & $-\mathrm{e}$ & $-\mathrm{e}$ & 5 \\
\hline Dans et-mek & ile, -de & ile, -de & ile, -de & ile, -de & ile, -de & 5 \\
\hline Davet et-mek & $-\mathrm{i}$ & $-\mathrm{i},-\mathrm{e}$ & $-i,-e$ & $-i,-e$ & $-\mathrm{i},-\mathrm{e}$ & 4 \\
\hline Değişstir-mek & $-\mathrm{i}$ & $-\mathrm{i}$ & $-\mathrm{i}$ & $-\mathrm{i}$ & $-\mathrm{i}$ & 5 \\
\hline De-mek & $\varnothing$ & $\varnothing,-\mathrm{i}$ & $\varnothing,-\mathrm{i}$ & $\varnothing,-\mathrm{i}$ & $\varnothing,-\mathrm{i}$ & 4 \\
\hline Ders çalış-mak & $\varnothing,-$ de & $\varnothing$ & $\varnothing$ & $\varnothing,-$ de & $\varnothing$, -de & 3 \\
\hline Devam et-mek & $-e$ & $-e$ & $-e$ & $-e$ & $-e$ & 5 \\
\hline Dile-mek & $\varnothing$, -den & $\varnothing$, -den & $\varnothing$, -den & $\varnothing$, -den & $\varnothing$, -den & 5 \\
\hline Dinle-mek & $\varnothing,-\mathrm{i}$ & $\varnothing,-\mathrm{i}$ & $\varnothing,-\mathrm{i}$ & $\varnothing,-\mathrm{i}$ & $\varnothing,-\mathrm{i}$ & 5 \\
\hline Dinlen-mek & $\varnothing,-$ de & $\varnothing$, -de & $\varnothing$, -de & $\varnothing$, -de & $\varnothing$,-de & 5 \\
\hline Doğ-mak & -de & - de & - de & - de & - de & 5 \\
\hline Dolaş-mak & -de & -de & -de & -de & -de & 5 \\
\hline Dön-mek & -den, ile & -den, ile & -den, ile & -den, ile & -den & 4 \\
\hline Dur-mak & $\varnothing,-$ de & $\varnothing,-$ de & $\varnothing,-$ de & $\varnothing,-$ de & $\varnothing,-$ de & 5 \\
\hline
\end{tabular}




\begin{tabular}{|c|c|c|c|c|c|}
\hline Duş al-mak & $\varnothing$ & $\varnothing$ & $\varnothing$ & $\varnothing$,-de & $\varnothing$ \\
\hline Eğlen-mek & $\varnothing$ & $\varnothing$ & $\varnothing$ & $\varnothing$ & $\varnothing$ \\
\hline El öpmek & $\varnothing$ & $\varnothing$ & $\varnothing$ & $\varnothing$ & $\varnothing$ \\
\hline Et-mek & $\varnothing$ & $\varnothing$ & $\varnothing$ & $\varnothing$ & $\varnothing$ \\
\hline Evlen-mek & ile,-de & ile,-de & ile,-de & ile,-de & ile,-de \\
\hline Fotoğraf çek-mek & $\varnothing$, -de, ile & $\varnothing$ & ile & -de & $\varnothing,-$ de \\
\hline Gecik-mek & $\varnothing,-\mathrm{e}$ & $\varnothing,-\mathrm{e}$ & $\varnothing,-\mathrm{e}$ & $\varnothing,-\mathrm{e}$ & $\varnothing,-\mathrm{e}$ \\
\hline Geç-mek & -i, -den & $\varnothing$ & $-\mathbf{i}$ & -den & ile \\
\hline Gel-mek & $\varnothing$, -den & $\varnothing$, -den & $\varnothing$, -den & $\varnothing$, -den & $\varnothing$, -den \\
\hline Gez-mek & $\varnothing,-$ de & $\varnothing,-$ de & $\varnothing$ & $\varnothing,-$ de & $\varnothing$, -de \\
\hline Gir-mek & $-e$ & $-e$ & $-e$ & $-e$ & $-e$ \\
\hline Git-mek & $\varnothing,-\mathrm{e}$ & $\varnothing,-\mathrm{e}$ & $\varnothing,-\mathrm{e}$ & $\varnothing,-\mathrm{e}$ & $\varnothing,-\mathrm{e}$ \\
\hline Golf oyna-mak & -de & $\varnothing$ & ile & $\varnothing$, -de & $\varnothing$ \\
\hline Gönder-mek & $\varnothing,-\mathrm{e}$ & $\begin{array}{l}\varnothing,-\mathrm{e}, \\
\text { ile }\end{array}$ & ile & $\varnothing,-\mathrm{e}$ & $\varnothing,-\mathrm{e}$ \\
\hline Görüş-mek & ile & ile & ile & ile & ile \\
\hline Gösteri yap-mak & $\varnothing$ & - de & $\varnothing$, -de & ile & $\varnothing$ \\
\hline Götür-mek & $-i,-e$ & $-i,-e$ & $-i,-e$ & $-i,-e$ & $-\mathrm{i}$ \\
\hline Hazırla-mak & $\varnothing,-\mathrm{i},-\mathrm{e}$ & $\varnothing,-\mathrm{i}$ & $\varnothing,-\mathrm{i}$ & $\varnothing,-\mathrm{i}$ & $\varnothing,-\mathrm{i}$ \\
\hline Hazırlan-mak & $\varnothing$ & $\varnothing$ & $\varnothing$ & $\varnothing$ & $\varnothing$ \\
\hline Heyecanlan-mak & $\varnothing$ & $\varnothing$ & $\varnothing$ & $\varnothing$ & $\varnothing$ \\
\hline Hisset-mek & $-\mathrm{i}$ & $-\mathrm{i}$ & $-\mathrm{i}$ & $-\mathrm{i}$ & $-\mathrm{i}$ \\
\hline Hoşlan-mak & -den & -den & -den & -den & -den \\
\hline İğne ol-mak & $\varnothing$ & $\varnothing$ & $\varnothing$,-de & $\varnothing,-$ de & $\varnothing$,-de \\
\hline İkram et-mek & $\varnothing,-\mathrm{e}$ & $\varnothing,-\mathrm{e}$ & $\varnothing,-\mathrm{e}$ & $\varnothing,-\mathrm{e}$ & $\varnothing,-\mathrm{e}$ \\
\hline İlgilen-mek & ile & ile & ile & ile & ile \\
\hline İnan-mak & $-\mathrm{e}$ & $-\mathrm{e}$ & $-e$ & $-\mathrm{e}$ & $-\mathrm{e}$ \\
\hline İnternete gir-mek & $\varnothing$ & $\varnothing$ & $\varnothing$ & $\varnothing$ & $\varnothing$ \\
\hline İzle-mek & $\varnothing,-\mathrm{i}$ & $\varnothing,-\mathrm{i}$ & $\varnothing,-\mathrm{i}$ & $\varnothing,-\mathrm{i}$ & $\varnothing,-\mathrm{i}$ \\
\hline Kahvaltı et-mek & $\varnothing$,-de,-ile & $\varnothing$ & $\varnothing,-$ de & $\varnothing,-$ de & $\varnothing,-$ de \\
\hline Kalk-mak & -de,-den & -de,-den & -de,-den & -de,-den & -de \\
\hline Kal-mak & -de & - de & - de & -de & -de \\
\hline Kapan-mak & $\varnothing,-$ de & $\varnothing,-$ de & $\varnothing$ & $\varnothing$,-de & $\varnothing$,-de \\
\hline Kapat-mak & $-\mathrm{i}$ & $-\mathrm{i}$ & $-\mathrm{i}$ & $-\mathrm{i}$ & $-\mathrm{i}$ \\
\hline Karşıla-mak & $-\mathrm{i},-\mathrm{de}$ & $-\mathrm{i}$ & $-\mathrm{i}$ & $-\mathrm{i}$ & $-\mathrm{i}$, de \\
\hline Kaşın-mak & $\varnothing,-\mathrm{i}$ & $\varnothing$ & $\varnothing,-\mathrm{i}$ & $\varnothing$ & $\varnothing,-\mathrm{i}$ \\
\hline Katıl-mak & $-e$ & $-\mathrm{e}$ & $-e$ & $-e$ & $-e$ \\
\hline Kavuş-mak & $-\mathrm{e}$ & -e, ile & -ile & $-e$, ile & -e, ile \\
\hline Kayak yap-mak & $\varnothing,-$ de & $\begin{array}{c}\varnothing, \text {-de, } \\
\text { ile }\end{array}$ & $\varnothing$ & $\varnothing$, ile & $\varnothing$, -de \\
\hline Kızar-mak & $\varnothing$ & $\varnothing$ & $\varnothing$ & $\varnothing$ & $\varnothing$, ile \\
\hline Kolonya dök-mek & $-e$ & $-\mathrm{e}$ & $-e$ & $-\mathrm{e}$ & $-e$ \\
\hline Kontrol et-mek & $\begin{array}{l}\varnothing,-i,- \\
\text { den, ile }\end{array}$ & $\varnothing,-\mathbf{i}$ & $-i$, ile & $\varnothing$, ile & $\varnothing$,-den \\
\hline Konuş-mak & ile & ile & ile & ile & ile \\
\hline Kork-mak & $\varnothing,-$ den & $\varnothing,-$ den & $\varnothing$, -den & $\varnothing,-$ den & $\varnothing$, -den \\
\hline Koru-mak & $-\mathrm{i}$ & $-\mathrm{i}$ & $-\mathrm{i}$ & $-\mathrm{i}$ & $-\mathrm{i}$ \\
\hline
\end{tabular}




\begin{tabular}{|c|c|c|c|c|c|}
\hline Koş-mak & $\varnothing,-$ de & $\varnothing$ & $\varnothing,-$ de & $\varnothing,-$ de & $\varnothing$ \\
\hline Koy-mak & $-i,-e$ & $-i,-e$ & $-i,-e$ & $-i,-e$ & $-i,-e$ \\
\hline Kullan-mak & $\varnothing,-\mathrm{i}$ & $\varnothing,-\mathrm{i}$ & $\varnothing,-\mathrm{i}$ & $\varnothing,-\mathrm{i}$ & $\varnothing,-\mathrm{i}$ \\
\hline Kutla-mak & $-\mathrm{i}$ & $-\mathrm{i}$ & $-\mathrm{i}$ & $-\mathrm{i}$ & $-\mathrm{i}$ \\
\hline Midesi bulan-mak & $\varnothing$, -den & $\varnothing$, -den & -den & -den & -den \\
\hline Nefret et-mek & -den & -den & -den & -den & -den \\
\hline Oku-mak & $\varnothing,-\mathrm{i}$ & $\varnothing,-\mathrm{i}$ & $\varnothing,-\mathrm{i}$ & $\varnothing,-\mathrm{i}$ & $\varnothing,-\mathrm{i}$ \\
\hline Otur-mak & -de & -de & -de & -de & -de \\
\hline Oyna-mak & $\varnothing$, ile & $\varnothing$, ile & $\varnothing$, ile & $\varnothing$, ile & $\varnothing$ \\
\hline Öğren-mek & $\varnothing,-\mathrm{i}$ & $\varnothing,-\mathrm{i}$ & $\varnothing,-\mathrm{i}$ & $\varnothing,-\mathrm{i}$ & $\varnothing,-\mathrm{i}$ \\
\hline Öğret-mek & $\varnothing,-\mathrm{i}$ & $\varnothing,-\mathrm{i}$ & $\varnothing,-\mathrm{i}$ & $\varnothing,-\mathrm{i}$ & $\varnothing,-\mathrm{i}$ \\
\hline Öksür-mek & $\varnothing$ & $\varnothing$ & $\varnothing$ & $\varnothing$ & $\varnothing$ \\
\hline Öp-mek & $-\mathrm{i}$ & $-\mathrm{i}$ & $-\mathrm{i}$ & $-\mathrm{i}$ & $-\mathrm{i}$ \\
\hline Özle-mek & $-\mathrm{i}$ & $-\mathrm{i}$ & $-\mathrm{i}$ & $-\mathrm{i}$ & $-\mathrm{i}$ \\
\hline Para çek-mek & $\varnothing$ & $\varnothing$ & $\varnothing$, -den & $\varnothing$, -den & $\varnothing$, -den \\
\hline Para topla-mak & $\varnothing$ & $\varnothing$ & $\varnothing$, -den & $\varnothing$, -den & $\varnothing$, -den \\
\hline Pişir-mek & $\varnothing,-\mathrm{i}$ & $\varnothing,-\mathrm{i}$ & $\varnothing,-\mathrm{i}$ & $\varnothing,-\mathrm{i}$ & $\varnothing,-\mathrm{i}$ \\
\hline Pişman ol-mak & $\varnothing,-\operatorname{den}$ & $\varnothing$, -den & $\varnothing$, -den & $\varnothing$, -den & $\varnothing$, -den \\
\hline Plan yap-mak & $\varnothing$ & $\varnothing$ & $\varnothing$ & $\varnothing$ & $\varnothing$ \\
\hline Pratik yap-mak & $\varnothing$ & $\varnothing$ & $\varnothing$ & $\varnothing$ & $\varnothing$ \\
\hline Saç kestir-mek & $-e$, ile & -e, -de & ile & $-\mathbf{e}$ & - de \\
\hline Salla-mak & $\varnothing,-\mathbf{i}$ & $-\mathbf{i},-e$ & ile & $\varnothing$ & $-\mathbf{i}$ \\
\hline San-mak & $\varnothing,-\mathrm{i}$ & $\varnothing,-\mathrm{i}$ & $\varnothing,-\mathrm{i}$ & $\varnothing,-\mathrm{i}$ & $\varnothing$ \\
\hline Satın al-mak & $\varnothing,-\mathrm{i}$, -den & $\begin{array}{l}\varnothing,-\mathrm{i},- \\
\text { den }\end{array}$ & -i, -den & $\begin{array}{c}\varnothing,-\mathrm{i},- \\
\text { den }\end{array}$ & $\varnothing,-\mathrm{i}$ \\
\hline Selam söyle-mek & $-\mathrm{e}$ & $-\mathrm{e}$ & $-\mathrm{e}$ & $-e$ & $-\mathrm{e}$ \\
\hline Sev-mek & $-\mathrm{i}$ & $-\mathrm{i}$ & $-\mathrm{i}$ & $-\mathrm{i}$ & $-\mathrm{i}$ \\
\hline Sik1l-mak & $\varnothing$, -den & $\varnothing$, -den & $\varnothing$, -den & $\varnothing$, -den & $\varnothing$, -den \\
\hline Sofra hazırla-mak & $-\mathbf{e}$ & $\varnothing$ & -de & $\varnothing,-\mathrm{e}$ & $\varnothing$, -de \\
\hline Sohbet et-mek & ile & ile & ile & ile & ile \\
\hline Sor-mak & $-i,-e$ & $-i,-e$ & $-i,-e$ & $-\mathrm{i},-\mathrm{e}$ & $-\mathrm{i},-\mathrm{e}$ \\
\hline Sosyal ol-mak & $\varnothing$ & ile & -de & $\varnothing$, -de & $\varnothing$, ile \\
\hline Söyle-mek & $-\mathrm{e}$ & $-\mathrm{e}$ & $-\mathrm{e}$ & $-\mathrm{e}$ & $-\mathrm{e}$ \\
\hline Spor yap-mak & $\varnothing,-$ de & $\varnothing,-$ de & $\varnothing,-$ de & $\varnothing,-\mathrm{de}$ & $\varnothing$ \\
\hline Stres at-mak & $\varnothing$ & $\varnothing$, ile & $\varnothing$ & $\varnothing$ & $\varnothing$, ile \\
\hline Sür-mek & $\varnothing,-\mathrm{i}$ & $\varnothing,-\mathrm{i}$ & $\varnothing,-\mathrm{i}$ & $\begin{array}{l}\varnothing,-\mathrm{i}, \\
\text { ile }\end{array}$ & $\varnothing,-\mathrm{i}$ \\
\hline $\begin{array}{l}\text { Tadı damağında } \\
\text { kalmak }\end{array}$ & - & - & - & - & - \\
\hline Tahlil yaptır-mak & $\varnothing$, -de & $\varnothing,-$ de & $\varnothing$, -de & $\varnothing$, -de & $\varnothing,-$ de \\
\hline Tamamla-mak & $-\mathrm{i}$ & $-\mathrm{i}$ & $-\mathrm{i}$ & $-\mathrm{i}$ & $-\mathrm{i}$ \\
\hline Tanı-mak & $-\mathrm{i}$ & $-i$ & $-i$ & $-\mathrm{i}$ & $-i$ \\
\hline Tanış-mak & ile & ile & ile & ile & ile \\
\hline Tansiyon ölçtür-mek & $\varnothing,-$ de & $\varnothing,-$ de & $\varnothing$, -de & $\varnothing$, -de & $\varnothing$, -de \\
\hline Tartıl-mak & $\varnothing,-$ de & $\varnothing,-$ de & $\varnothing$, -de & $\varnothing,-$ de & $\varnothing$, -de \\
\hline Tasarla-mak & $\varnothing,-\mathrm{i}$ & $\varnothing,-\mathrm{i}$ & $\varnothing,-\mathrm{i}$ & $\varnothing,-\mathrm{i}$ & $\varnothing,-\mathrm{i}$ \\
\hline Tedavi ol-mak & $\varnothing,-\mathrm{de}$ & $\varnothing,-\mathrm{de}$ & $\varnothing,-$ de & $\varnothing,-$ de & $\varnothing$, -de \\
\hline
\end{tabular}




\begin{tabular}{|c|c|c|c|c|c|}
\hline Tekrar et-mek & $-\mathrm{i}$ & $-\mathrm{i}$ & $-i$ & $-\mathrm{i}$ & $-i$ \\
\hline Telefon et-mek & $-e$ & $-\mathrm{e}$ & $-\mathrm{e}$ & $-e$ & $-\mathrm{e}$ \\
\hline Temizle-mek & $-\mathrm{i}$, ile & $-\mathrm{i}$ & $-\mathrm{i}$, ile & $-\mathrm{i}$ & $-\mathrm{i}$, ile \\
\hline Tirman-mak & $-\mathrm{e}$, ile & $-e$ & $-e$ & $-\mathrm{e}$ & $-\mathrm{e}$, ile \\
\hline Topla-mak & $-\mathrm{i}$ & $-\mathrm{i}$ & $-\mathrm{i}$ & $-\mathrm{i}$, ile & $-\mathrm{i}$, ile \\
\hline Uğur getir-mek & $-\mathrm{e}$ & $-\mathrm{e}$ & $-\mathrm{e}$ & $-\mathrm{e}$ & $-e$ \\
\hline Uyu-mak & $\varnothing$, -de & $\varnothing$, -de & $\varnothing$, -de & $\varnothing$, -de & $\varnothing$, -de \\
\hline Uzan-mak & $-e,-$ de & $-e,-$ de & -e, -de & $-e,-$ de & -e, -de \\
\hline Üfle-mek & $-\mathrm{i},-\mathrm{e}$ & $-\mathrm{i},-\mathrm{e}$ & $-i,-e$ & $-\mathrm{i},-\mathrm{e}$ & $-i,-e$ \\
\hline Vakit geçir-mek & $\varnothing$, -de & -de, ile & $\varnothing$ & - de & ile \\
\hline Var-mak & $-e$ & $-\mathrm{e}$ & $-e$ & $-e$ & $-\mathrm{e}$ \\
\hline Vedalaş-mak & ile & ile & ile & ile & ile \\
\hline Ver-mek & $\varnothing,-\mathrm{e}$ & $\varnothing,-\mathrm{e}$ & $\varnothing,-\mathrm{e}$ & $\varnothing,-\mathrm{e}$ & $\varnothing,-\mathrm{e}$ \\
\hline Yak-mak & $-\mathrm{i}$, ile & $-\mathrm{i}$ & $-\mathrm{i}$ & $-\mathrm{i}$ & $-\mathrm{i}$ \\
\hline Yap-mak & $\varnothing,-\mathrm{i}$ & $\varnothing$ & $\varnothing,-\mathrm{i}$ & $\varnothing,-\mathrm{i}$ & $\varnothing,-\mathrm{i}$ \\
\hline Yardım et-mek & $-e$ & $-e$ & $-e$ & $-e$ & $-e$ \\
\hline Yardım iste-mek & -den & -den & -den & -den & -den \\
\hline Yaşa-mak & - de & $-\mathrm{de}$ & - de & - de & - de \\
\hline Yaşlan-mak & $\varnothing$ & $\varnothing$ & $\varnothing$ & $\varnothing$ & $\varnothing$ \\
\hline Yat-mak & $-\mathrm{de}$ & -de & $\varnothing,-$ de & $\varnothing,-$ de & $\varnothing$,-de \\
\hline Yaz-mak & $\varnothing,-\mathrm{i}$ & $\varnothing,-\mathrm{i}$ & $\varnothing,-\mathrm{i}$ & $\varnothing,-\mathrm{i}$ & $\varnothing,-\mathrm{i}$ \\
\hline Ye-mek & $\varnothing,-\mathrm{i}$ & $\varnothing,-\mathrm{i}$ & $\varnothing,-\mathrm{i}$ & $\varnothing,-\mathrm{i}$ & $\varnothing,-\mathrm{i}$ \\
\hline Yen-mek & $-\mathrm{i}$ & $-\mathrm{i}$ & $-\mathrm{i}$ & $-\mathrm{i}$ & $-\mathrm{i}$ \\
\hline Yer ayırt-mak & -den, ile & -den & -den, ile & -den & -den \\
\hline Y1ka-mak & $-\mathrm{i}$, ile & $-\mathrm{i}$ & $-\mathrm{i}$ & $-\mathrm{i}$ & $-\mathrm{i}$, ile \\
\hline Yorul-mak & $\varnothing$ & $\varnothing$ & $\varnothing$ & $\varnothing$ & $\varnothing$ \\
\hline Yürü-mek & $\varnothing,-\mathrm{e}$ & $\varnothing,-\mathrm{e}$ & $\varnothing,-\mathrm{e}$ & $\varnothing,-\mathrm{e}$ & $\varnothing,-\mathrm{e}$ \\
\hline Yüz-mek & $\varnothing$, -de & $\varnothing$, -de & $\varnothing$, -de & $\varnothing$, -de & $\varnothing,-$ de \\
\hline Zaman geçir-mek & $\varnothing,-$ de & -de, ile & $\varnothing$ & -de & ile \\
\hline Ziyaret et-mek & $-\mathrm{i}$ & $-\mathrm{i}$ & $-\mathrm{i}$ & $-\mathrm{i}$ & $-\mathrm{i}$ \\
\hline
\end{tabular}

Çalışma grubunda yer alan öğreticiler sırasıyla banyo yap-mak, fotoğraf çek-mek, geç-mek, golf oyna-mak, gösteri yap-mak, kayak yap-mak, kontrol et-mek, saç kestirmek, salla-mak, sofra hazlrla-mak, sosyal ol-mak, vakit geçir-mek ve zaman geçirmek fiilleri üzerinde görüş ayrılığına düştüğü ve hiçbir öğreticinin tadı damağında kalmak deyimine ilişkin bir cevap vermediği tespit edilmiştir. $\mathrm{Bu}$ fiillerde düşülen görüş ayrılığı cevap vermeme durumu güvenirlik testinin sonucunu \%91 olarak belirlenmesini sağlamıştır. Görüş ayrılığına sebep olan fiillerin genellikle $a d+y a r d ı m c ı ~ f i i l(e t-m e k$, ol-mak, eyle-mek, kll-mak) şeklinde kurulan yapılardan olması ise dikkat çekici bir durumdur.

Listede yer alan fiillerden 50 tanesi bir durum ekini gösteren yalnızca bir kodlayıcı ile işaretlenmiştir. Bu sayısal değerin oransal karşılığı ise \%31 olarak hesaplanmıştır. 54 tanesi bir durum ekini gösteren yalnızca iki kodlayıcı ile gösterilmektedir. $\mathrm{Bu}$ sayısal değerin oransal karşılığ $\% 33$ olarak hesaplanmıştır. Yalnızca atla-mak fiili bir durum ekini gösteren üç kodlayıcı ile işaretlenmiştir. Geriye kalan 56 tane fiil ise diğer şekillerde işaretlenmiştir. 
Çalışmanın omurgasını oluşturan Tablo 3'te yer alan bilgilerin tek parça olarak verilmesi zorunluluğu öğretici görüşlerinin frekans aralıkları $(f)$ ile ilgili bilgi verme durumunu ortaya çıkarmıştır. Bu bağlamda 10 fiil 0, 4 fiil 2, 19 fiil 3, 19 fiil 4 ve 109 fiil 5 frekans aralığında değerlere sahiptir. Yani fiiller ile ilgili \%67 oranında ortak bir frekans değeri sağlandığı hesaplanmıştır.

\section{Tartışma ve Sonuç}

$\mathrm{Bu}$ çalışmada yabancı dil olarak Türkçenin öğretiminde kullanılan temel seviyenin A1 kurunda kullanılan fiillerin biçimbilgisel istemlerle nasıl kullanıldığına dair öğretici görüşlerinin yer aldığ 1 bir durum çalışması uygulanmıştır. Çünkü durum çalışmalarında Davey'in (2009) de belirttiği üzere; gerçekte ortamda neler olduğuna bakma, sistematik bir biçimde verileri toplama, analiz etme ve sonuçlar ortaya koyma yolu benimsenmektedir.

Çalışmaya konu olan fiiller ile ilgili yüksek güvenirlik oranı öğretici yeterliğinin ne kadar önemli olduğunu göstermektedir. Çünkü dil öğretiminin temel seviyesinde sınıf içerisindeki mutlak kaynaklardan en önemlisi öğreticidir. Dil öğrenen bireyler hedef dilin dünyası içerisine öğreticinin ortaya koyduğu bakış açısından giriş yapmaktadırlar. $\mathrm{Bu}$ bakış açısı fiillerin sahip oldukları anlama ve bağlamdaki özelliğine göre biçimbilgisel istem görünümlerine sahip oldukları kuralıdır. Nurlu ve diğerlerine (2018) göre Türkçedeki fiiller durum ekleriyle kullanılırlar. Durum ekleri cümle içinde adların diğer sözcüklere karşı durumunu belirten bir özellik taşır. Cümledeki fiiller bu durum eklerine göre bir anlam kazanır veya anlamlanırlar. Melanlığlu (2012) benzer çalışmasında soyut nitelik taşıyan hâl eklerinin öğretiminde somutlaştırmadan yapılmasını, öğreticilerin, bu eklerin kullanımını pekiştirmek için uygulama sayısını çoğaltmasını, durum eklerinin öğretimi sırasında sadece hedef dilin bir başka ifadeyle Türkçenin imkânlarından yararlanılmasını önermektedir. Ayrıca her bir fiilin çeşitli bağlamlarda yüklendiği istemin öğretici tarafından bilinerek öğretilmesi farkındalığın artmasına da sebep olacaktır. Sakallı (2006)'ya göre ismin durum ekleri sadece isimlerin aldığı ekler olarak değil, fiil istemleri olarak öğretilmeli, hangi fiilin hangi durum ya da durumları alabileceği özellikle kelime öğretimi çalışmalarının temelini oluşturmalıdır. Yapılan benzer bir çalışmada (Dolunay vd., 2020) öğrenme seviyelerinin yükselmesine rağmen istem yanlışlarının devam etmesi önemli bir sorun olarak değerlendirilmektedir.

Öğreticilerin görüş ayrılığı yaşadığı 14 fiilin büyük kısmı ad+yardımcı fiil(etmek, ol-mak, eyle-mek, kıl-mak) şeklinde oluşturulan yapılardır. Bu tür yapılar ele alınırken sahip olmaları gereken zorunlu istemlerle birlikte işlenmelidirler. Dolunay ve diğerleri (2020) bütün seviyeleri içeren çalışmalarında ad+yardımcı fiilden oluşan toplam 28 tane yapıyla ilgili biçimbilgisel yanlış yapıldığını tespit etmişlerdir. $\mathrm{Bu}$ durum ilgili fiillerden birkaç örnek ile şu şekilde somutlaştırılmalıdır:
a. $\quad$ Ahmet $+\varnothing$ banyo yaptl.
b. $\quad$ Ahmet $+\varnothing$ yurt + ta banyo yaptt.
c. $\quad$ Ahmet $+\varnothing$ yurt + ta kese + yle banyo yaptt. 
Örneklerden hareketle cümleyi meydana getiren ve bağlamı tamamlayan istemlerin altları çizilmiştir. $a$ örneğinde fiili yapan unsur herhangi bir isteme ihtiyaç duymazken $b$ örneğinde yönelmeye dayalı bir yer tamlayıcısına, $c$ örneğinde ise vasıtayı anlatan bir araç-gerece ihtiyaç duymaktadır. Böylelikle bağlamın genişlemesiyle birlikte fiilin ihtiyaç duyduğu istemler değişiklik göstermektedir. Dolayısıyla bu seviyede bu tür birleşik yapılar çeşitli örneklerle ele alınarak öğrenciye sunulmalıdır.

Öğreticilerin kodlama sıklıkları her fiil için değişkenlik gösterirken bu durumun sebebi ise fiillerin kullanıldığı cümlelerin bağlam genişliğidir. Yani bir fiil en az bir veya sahip olduğu anlama ve bağlam genişliğine göre birden fazla biçimbilgisel istem yüklenmektedir. Bu durum ise karmaşaya yol açmaktadır. "Belirtildiği gibi fiiller, bazı tamlayıcıları birinci dereceden ve çok sık olarak almaktadır. Bu durum onların bu tamlayıcılarla yapısal bir birlik, bir öbek oluşturduğu izlenimini vermektedir. Ancak bu, büyük ölçüde, bazı fiillerin bazı tamlayıcılarla sıkça kullanılmasıyla ve bazı fiillerin de yalnızca bir veya birkaç tamlayıcıyı almalarıyla ilgilidir (Özezen, 2007, s. 156). Yukarıda yer alan $a, b, c$ örneklerinden hareketle cümleleri oluştururken öğrencinin seviyesi ve fiillerin bağlam içinde kullanımı göz önünde bulundurularak öğretim yapıldığı takdirde bu karmaşa sona erecektir. Ayrıca bu fiiller ile ilgili ders kitaplarının uygun yerlerinde madde başı, biçimbilgisel istem ve örnek cümle şeklinde sözlüksel bir bilgilendirme hem öğretici hem de öğrenciler için yol gösterici olacaktır. "Fiillerin aldıkları tamlayıcılar bakımdan özelliklerinin tam olarak belirlenmesi, aldıkları tamlayıcıların fiilin anlamını ne ölçüde etkilediği veya değiştirdiği ve cümlede hangi tamlayıcı hangi öge olur, sorularına da tam bir yanıt verilmesi derlem çalışmaları ile olanaklı görünmektedir" (Özezen, 2007, s. 154). Bu bağlamda Nurlu ve diğerleri (2018)'nin çalışması yol gösterici bir başucu kaynağı niteliğindedir.

Çalışmanın konusu ve içeriği gereği A1 seviyesindeki fiiller inceleme örneklemini oluşturmaktadır. Bu noktada fiillerin daha ziyade etken çatılı olarak kullanılması esastır. Yer ayırt-mak, tahli yaptır-mak, tansiyon ölçtür-mek, saç kestirmek gibi ettigen çatılı fiiller istem değiştirme özelliğine sahip yapılardır. "Bir eylemin istem çerçevesine sebep olan rolündeki bir üyenin eklenmesi eylemin yönetici konumunda olduğu tümcede köklü bir değişikliğe yol açar. Çünkü sebep olan rolünü yüklenen üye daima özne konumunu ele geçirir ve eskiden özne konumunda olan üye ettirgenleşme sonrası meydana gelen yeni eylemin istem yapısında farklı bir dil bilgisel ilişki ile yer alır (Aydın Özkan, 2017, s. 142).

Bir önceki paragraftaki duruma benzer olarak deyimleşmiş kalıp ifadelerin kullanımı da ele alınması gereken bir konudur. Tablo 3.'te yer alan Tadı damağında kal-mak deyimi kendisini oluşturan kelimelerin anlamlarının değişmesiyle anlambilgisel bir değişim yaşar. Dolayısıyla durum daha karmaşık bir hâl alarak kavram karmaşası yaşanabilir (bkz. Aydın Özkan, 2017, s. 247-251). Çünkü deyimi oluşturan her bir ifade bir öncekine veya sonrakine bağlanarak bağlamı tamamlar:

d. Gezinin tadı damağımda kaldı.
e. Kitabı̆ tadı damă̆ımda kaldı.




\section{f. Yemeğin tadı damăğımda kaldı.}

İlgili örneklerde tadı bir isim tamlamasının ikinci unsuru olarak - $i$ tamlanan ekini almıştır. Dolayısıyla kendinden önce - In eki ile biten bir tamlayana ihtiyaç duymaktadır. Bu durum ise biçimgisel istem başlığı ile örtüşmemektedir ve başka bir dil bilgisi konusunu işaret etmektedir. Özetle bu seviyede kullanılan deyimler yine biçimbilgisel istem görünümleri açısından ele alınmalıdır.

\section{Etik Bildirim}

Makalenin yazarı olarak, bu makalede bilimsel ve etik kurallara uyulduğunu beyan ederim.

\section{Kaynakça}

Açık, F. (2008). Türkiye'de yabancılara Türkçe öğretilirken karşılaşılan sorunlar ve çözüm önerileri. Uluslararası Türkçe Eğitimi ve Öğretimi Sempozyumu. KKTC.

Akıncı, N. (2007). Türkçe Sözlük'tek fiillerin sinıflandırılması ve gövde eklerinin işlevsel tasnifi [Yayımlanmamış yüksek lisans tezi]. Cumhuriyet Üniversitesi.

Atacık, D. A. (2008). Türkiye Türkçesinde istem (valenz) [Yayımlanmamış yüksek lisans tezi]. Fatih Üniversitesi.

Atagül, Y. Y., \& Cevher, Ö. Y. (2015). Türkçenin yabancı dil olarak öğretiminde hâl eki sorunsalı (Sakarya Üniversitesi örneği). TÜRÜK Uluslararası Dil, Edebiyat ve Halkbilimi Araştırmaları Dergisi, 3(5), 294-332.

Banguoğlu, T. (1990). Türkçenin grameri (3. Baskı). Tük Dil Kurumu Yayınları.

Barlas, S. (2015). Kırgız Türkçesinde istem(valenz) [Yayımlanmamış yüksek lisans tezi]. Gazi Üniversitesi.

Baytürk, F. (2015). Türkmen Türkçesinde fiillerin istemi [Yayımlanmamış yüksek lisans tezi]. Ordu Üniversitesi.

Boylu, E. (2014). Yabanc1 dil olarak Türkçe öğrenen temel seviyedeki İranlı öğrencilerin yazma problemleri. Zeitschrift für die Welt der Türken Journal of World of Turks, VI (2), 335-349.

Çangal, Ö., \& Başar, U. (2018). Yabancılara Türkçe öğretiminde ad durum eklerinin yan işlevlerinin öğretilmesi. 21. Yüzyılda Eğitim ve Toplum, 7(19), 155-189.

Çetinkaya, C. (2012). Kazak Türkçesinde fiilin istemi: Valenz [Yayımlanmamıs yüksek lisans tezi]. Celal Bayar Üniversitesi.

Çiçekli, H. (2013). Azerbaycan Türkçesinde fiillerin istemi (Yayımlanmamış Yüksek lisans tezi). Ordu Üniveritesi.

Çimen, F. (2009). Özbek Türkçesinde istem (valenz) [Yayımlanmamış yüksek lisans tezi]. Fatih Üniversitesi.

Davey, L. (2009). Durum çalışması değerlendirmelerinin uygulaması. Gökçek, T. (Çev.). Illköğretim Online, 8(2), 1-3.

Demirci, K. (2007). Türkçedeki hâl eki nöbetleşmeleri üzerine. Karaman Dil-Kültür ve Sanat Dergisi, 126-139.

Dizdaroğlu, H. (1963). Türkçede fiiller. Ankara Üniversitesi Basımevi. 
Doğan, N. (2011). Türkiye Türkçesi fiillerinde isteme göre anlam değişiklikleri [Yayımlanmamış yüksek lisans tezi]. Ondokuz Mayıs Üniversitesi.

Dolunay, S. K., İpek, O., \& Karabuğa, H. (2018). Türkçe öğrenen Arap öğrencilerin yazılı anlatımlarındaki biçimbilgisel istem yanlışları. Akşemseddin Uluslararası İnsan, Toplum,Spor Bilimleri Sempozyumu. Çorum.

Dolunay, S. K., Karabuğa, H., \& İpek, O. (2020). Türkçe öğrenen Arap öğrencilerin biçimbilgisel istem yanlışları: Fiiller üzerine bir sıklık çalışması. Dil Eğitimi ve Araştırmaları Dergisi, 6(2), 508-530. https://doi.org/10.31464/jlere.748071

Ergin, M. (1992). Türk dil bilgisi (19. Baskı). Bayrak Yayınları.

Ersoy, F. (2006). Moğolca ve Türkçede fiil-tamlayıcı ilişkileri. Selçuk Üniversitesi Türkiyat Araştırmaları Dergisi, 20, 81-98.

Güller, N. (2019). Başkurt Türkçesinde fiil-tamlayıcı ilişsisi [Yayımlanmamış yüksek lisans tezi]. Ankara Hacı Bayram Veli Üniversitesi.

Gümüşatam, G. (2014). Türkiye Türkçesi Ağız Sözlüklerinin hazırlanmasında istem (Valenz) verilerinin gerekliliği üzerine. Turkish Studies. Volume 9(6), 419-439.

İltar, L., \& Dündar, S. A. (2018). Suriyeli öğrencilere Türkçenin yabancı dil olarak öğretiminde kullanılan öğretim setleri hakkında karşılaştırmalı bir değerlendirme çalışması. 21. Yüzyılda Eğitim ve Toplum, 7(20), 523-539

Kahraman, T. (1996). Çağdaş Türkiye Türkçesindeki fiillerin durum ekli tamlayıcıları. Türk Dil Kurumu Yayınları.

Kara, M. (2010). Gazi Üniversitesi TÖMER öğrencilerinin Türkçe öğrenirken karşılaştıkları sorunlar ve bunların çözümüne yönelik öneriler. Türk Eğitim Bilimleri Dergisi, VIII(3), 661-696.

Kara Özkan, N. (2020). Yabancı dil olarak Türkçe kelime öğretimi üzerine bir değerlendirme. Bayterek Uluslararası Akademik Araştırmalar Dergisi, 3(2), 126-139. https://doi.org/10.48174/buaad.826371

Karababa, C. (2009). Yabancı dil olarak Türkçe öğretimi ve karşılaşılan sorunlar. Ankara Üniversitesi Eğitim Bilimleri Fakültesi Dergisi, 42(2), 265-277.

Karahan, L. (1997). Fiil-tamlayıcı ilişkisi üzerine. Türk Dili, 549, 209-213.

Korkmaz, Z. (1995). Batı Anadolu ağızlarında yazı dilinden ayrılan isim çekim ekleri ve fonologie-morpholgie bağlantısı. Türk Dili Üzerine Araştırmalar II, 222-231.

Korkmaz, Z. (2003). Türkiye Türkçesi Grameri (Şekil Bilgisi). Türk Dil Kurumu Yayınları.

Melanlığlu, D. (2012). Yabancılara Türkçe öğretenlerin hâl eklerinin öğretimine ilişkin görüşleri: nitel bir araştırma. Turkish Studies, VII(4), 2401-2411.

Mert, O. (2003). Türkçede hâl kategorisi ve öğretimi. Atatürk Üniversitesi Türkiyat Araştırmaları Enstitüsü Dergisi, XXI, 25-31.

Miles, M. B., \& Huberman, A. M. (1994). Qualitative data analysis:An expanded sourcebook. (2nd Edition). SAGE Publications.

Nurlu, M., Özkan, N., Kutlu, A., Korkmaz, C. B., \& İlgün, K. (2017). Yabancılar için Türkçe fiiller sözlüğ̈̈ (Fiilerin durum ekleriyle kullanımı). Kalem Kitap. 
Ozil, Ş. (1990). Valenzwörterbuch Deutsch-Turkish, arbeiten zur mehrssprachigkeit. Hamburg.

Özezen, M. Y. (2007). Türkçe dil bilgisinde durum ve tamlayıcı konusu. Türk Dili Araştırmaları Ylllığl - Belleten, 55(1), 145-164.

Özkan, A. (1991). Türkçede fiil-tamlayıcı ilişkisi ve fiillerin istem değiştirmesi. ArayışlarInsan Bilimleri Araştırmaları, 1, 125-150.

Özkan, I. A. (2017). Evrensel dilbilgisi ve Türkçede istem (Valenz). [Yayımlanmamış doktora tezi]. Hacettepe Üniversitesi.

Sakallı, E. (2016). Yabancı dil olarak türkçe öğretiminde Türk soylu öğrencilerle Türk soylu olmayan öğrencilere durum eklerinin öğretilmesi meselesi. Uşak Üniversitesi Eğitim Araştırmaları Dergisi, II(2), 101-108.

Silverman, D. (2001). Interpreting qualitative data: Methods for analysing talk, text and interaction. SAGE Publication.

Şahin, E. Y. (2013). Yabancı dil olarak Türkçe öğrenen öğrencilerin yazılı anlatımlarındaki ek yanlışları. Tarih Okulu Dergisi, VI(15), 433-449.

Uğurlu, M. (2001). Türk lehçelerinin aktarımında valenz sözlüklerinin önemi. Uluslararası Sözlükbilim Sempozyumu Bildirileri, 197-206. Gazimağusa: Doğu Akdeniz Üniversitesi.

Ustabulut, M. Y. (2020). Yabancı dil olarak Türkçenin öğretiminde yansitıcı düşünme becerisi. Hiperyayın.

Uzun, N. E. (2004). Dünya dillerinden örnekleriyle dilbilgisinin temel kavramları Türkçe üzerine tartışmalar. Türk Dilleri Araştırmaları Dizisi: 39.

Uzunboy, H. (2008). Türkmen Türkçesinde istem (Valenz) [Yayımlanmamış yüksek lisans tezi]. Fatih Üniversitesi.

Uzunkaya, D. (2018). Altun Yaruk Maitrisimit ve Huastuanift örneğinde eski Uygur metinlerinde istem ve bağımlılık [Yayımlanmamış doktora tezi]. Pamukkale Üniversitesi.

Vardar, B. (2002). Açıklamalı dilbilim terimleri sözlüğüu. Multilingual Yayınları.

Yalkın, O. A. (2016). Yunus Emre Divanı'nda fiil-tamlayıcı ilișkisi. İnsan ve Toplum Bilimler Araştırmaları Dergisi, 5(6), 1501-1519. https://doi.org/10.15869/itobiad.256024

Yıldırım, A., \& Şimşek, H. (2012). Sosyal bilimlerde nitel araştırma yöntemleri. Seçkin Yayınları.

Yılmaz, N. (2016). Tatar Türkçesinde fiillerin istemi [Yayımlanmamış yüksek lisans tezi]. Ordu Üniversitesi.

\section{Extended Abstract}

Verbs can have different valency in different sentences where the same verb is used in different meanings. In fact, a verb may need more than one valency in the same sentence. Although this situation is known as the acquisition process for those who use Turkish as their mother tongue, it is a teaching process for those who learn as their target language. So, an individual whose native language is Turkish does not need any additional information on which verb to use for which morphological 
valency, whereas an individual who learns Turkish should have knowledge of the rules. In studies on the Turkic language, the concept of morphological valency is met with the concepts of case suffixes. The use and teaching of these suffixes begin almost in the first lessons of the A1 level in teaching Turkish as foreign language. At this point, the A1 level has a crucial place in the teaching process as it is a beginning where basic information about the Turkish language is given. These suffixes correspond to universal grammar and can refer to all other elements that are dependent on verbs in sentences. In fact, people who learn Turkish as the target language learn their morphological valency along with verbs. In other words, along with the case suffixes, they learn in which verbs and contexts these suffixes are used. While these suffixes are being taught to foreigners, they are coded as nominative, accusative, dative, locative, ablative, and instrumental cases. The resource textbooks that will provide access to these rules and the teachers who will teach these rules are of great importance for the people who learn Turkish as a target language. Therefore, teachers who are equipped with correct verb usage and correct information are lifebuoy for students.

This study was prepared with a case study, which is one of the qualitative research methods. Case study is the research method used to understand and define the causes and consequences of this case when the researcher has no effect on the variables. In the case study, a detailed description and examination of a research subject with defined limits is in the real environment. In the study, "What is the reliability of the morphological valency knowledge of those who teach Turkish at A1 level?" the answer to the question was sought. In order to determine whether there is a consistency among the tutorials for verbs in the A1 level.

In the study, 161 verbs were made into a list by the researcher in order to be given to the instructors to work with, within the scope of coder reliability. Participants were asked to mark the actant boxes of the morphological valency above the verbs in the lists presented to them. The answer sheets given to the lists created separately for each tutorial were given numbers from one to five regardless of their demographic information. After the markings made by the participants, the lists with the verbs were analyzed in order to calculate the coder reliability. In this context, the coder reliability among the 5 teachers who participated in the study was calculated using Miles and Huberman's (1994) formula (Reliability Percentage = Agreement / (Total Agreement + Disagreement) x 100. In this case, the reliability was calculated as $147 /(147+14) \times 100=91 \%$. The obtained qualitative data were analyzed in terms of their quantity and frequency values and how many formal verbs were used with informational request were calculated with their numerical and proportional values.

By listing the verbs collected from the study material in alphabetical order and marking the case suffixes with short names, the common answers of the trainers were shown in the form of frequency range. The deciphered form of the answers of the study group is included in the table. It is remarkable that the verbs that cause disagreement are generally structured in the form of noun + auxiliary verb. 50 of the verbs in the list are marked with only one encoder showing a case suffix. The proportional equivalent of this numerical value has been calculated as $31 \%$. 54 of them are shown with only two encoders showing a case suffix. The proportional equivalent of this numerical value has been calculated as $33 \%$. Only one verb is 
marked with three encoders indicating a case suffix. The remaining 56 verbs are marked in other ways. It has been calculated that a common frequency value of $67 \%$ is provided for verbs.

The high reliability rate about the verbs subject to the study shows how important the instructional efficacy is. Because at the basic level of language teaching, the most important of the absolute resources in the classroom is instructive. Language learners enter the world of the target language from the point of view set forth by the instructor. This point of view is the rule that verbs have morphological prompting appearances according to their meaning and context. Structures consisting of noun + auxiliary verb generally take affixes not according to verbs but according to meaning. Therefore, at this level, such combined structures should be presented to the student by taking various examples. In addition, a lexical information in the form of an item, morphological request and sample sentence in the appropriate parts of the textbooks about these verbs will be both instructive and guiding for students. Since causative verbs have the ability to change the will, active verbs should generally be used at this level. The use of idiomatic expressions should also be done by teaching the morphological prompts they have. 